\title{
Non-linearity in Testing for Fiscal Sustainability
}

\author{
Roberto Ricciuti* \\ Dipartimento di Economia Politica \\ Università degli Studi di Siena \\ Piazza San Francesco 7, \\ 53100 Siena, Italy \\ Email: ricciuti@unisi.it
}

\begin{abstract}
In this paper we characterise fiscal policy in terms of non-linear processes. We find that government spending and taxes can be described as being non-linear trend stationary processes instead of unit roots. A long run equilibrium relationship - a non-linear co-trend - does exist between the two series, fulfilling the intertemporal government budget constraint. We use Italian data spanning from 1861 to 1998.
\end{abstract}

Keywords: taxes, government expenditure, intertemporal government budget constraint, non-linear trend stationarity, non-linear co-trending.

JEL Classification nos.: C22, C32, E62, H62.

* Comments by Alastair Hall on a previous paper with a related topic led to the reasoning behind this work. David Cushman provided useful insights. Comments from Pier Paolo Pierani also improved the paper. I wish to thank them without implications. 


\section{Introduction}

Although it is common practice to treat macroeconomic variables as unit root processes, an increasing number of papers maintain that this conclusion may be misleading. For example, if a time series is trend stationary and the unit root hypothesis is tested against stationarity, the null hypothesis is likely to prevail because a unit root and a trend stationarity process may look quite similar (e.g., Phillips and Perron, 1988). Moreover, if a series has structural breaks, and these breaks are not taken into account, the unit root hypothesis is likely to be accepted, whereas it is likely to be rejected when breaks are accounted for (e.g., Zivot and Andrews, 1992). The idea that macroeconomic time series can be characterised as non-linear trend stationary processes is becoming more popular also because of an increasing concern in structural breaks. Indeed, the unit root with break hypothesis of Perron (1989) is a special case of non-linear trend stationarity. For processes that are stationary about non-linear deterministic time trends, non-linear cotrending is the phenomenon whereby one or more linear combinations of the time series are stationary about a linear trend and a constant, and hence have common non-linear deterministic time trends (Bierens, 2000).

Until now the use of these concepts has been limited to monetary issues, namely the relationship between interest rates and inflation (Bierens, 1997, 2000), and money demand (Cushman, 2002). Our task is to apply this analytical framework to fiscal policy, since there is increasing evidence that it is characterised by non-linear effects. Notably, most of these studies have a cross-section dimension, whereas here we consider the historical developments of a single country from times when government expenditure was a small proportion of the GDP with dramatic war shocks, to times when the public sector accounts for a significant part of the GDP with a steady increase. In particular, we consider the 
issue of the inter-temporal government budget constraint that has been extensively analysed via the unit root and cointegration approach. We use Italian data because of its historical and contemporary high levels of government deficit and debt, and we concentrate on long-run behaviour (1861-1998) because the financing needs of the two wars and of the great depression provide real test cases. The notion of non-linear trend stationarity is particularly useful for the problem at hand, since linear trend stationarity and unit root (with constant drift) hypotheses imply that the structure of the economy does not change over time, which is rather implausible for data spanning more than one century.

The paper is organised as follows: Section 2 reviews issues in fiscal sustainability and surveys previous empirical results. Sections 3 and 4 present the empirical methodology used here and the results, respectively. Conclusions are drawn in the final Section.

\section{Fiscal sustainability: theory and empirics}

As individuals, governments face an inter-temporal budget constraint (IGBC). Accordingly, they can run a large deficit for a short to medium term, but in the long run it is assumed that they cannot play a Ponzi game. If the government issues one-period debt, the real value of the outstanding debt $b_{t}$, in the discrete-time version, evolves according to:

$$
b_{t+1}=(1+r) b_{t}+g_{t}-\tau_{t}-s_{t},
$$


where $r$ is the real, constant interest rate, $g_{t}$ is real government expenditures net of interest, $\tau_{t}$ is real tax revenues, $s_{t}=\left(M_{t+1}-M_{t}\right) / P_{t}$ is real revenue from seigniorage when $M_{t}$ is the nominal supply of high powered money, and $P_{t}$ is the price level. Taking the expected values of (4) and solving through iteration, we obtain the IGBC:

$$
b_{t}=-E_{t} \sum_{j=0}(1+r)^{-(j+1)}\left(g_{t+j}-\tau_{t+j}-s_{t+j}\right)+\lim _{j \rightarrow \infty} E_{t}(1+r)^{-(j+1)} b_{t+j+1},
$$

where $\mathrm{E}($.$) denotes the expectation operator conditional to information at time t$. From the second term of the right-hand side of eq. (2), we impose the transversality condition:

$$
\lim _{j \rightarrow \infty} E_{t}(1+r)^{-(j+1)} b_{t+j+1}=0
$$

The government budget constraint is fulfilled, or in other words, fiscal policy is sustainable in the long run, if the present value of government spending equals the present value of taxes. The analysis of this issue has been carried out using cointegration. The rationale is that if revenue and government spending are non-stationary series, and if they are cointegrated, i.e. there is a linear combination of the two series which is stationary (Engle and Granger, 1987), they do not drift apart and then the government obeys to its inter-temporal budget constraint. Another method (Hamilton and Flavin, 1986) looks at the stationary properties of the stock of public debt. If the debt series is stationary, the debt is sustainable, otherwise the IGBC is not fulfilled. An important issue is whether or not interest payments should be included in the constraint. McCullum (1984) argued that a constant, positive deficit (excluding interest payments) could not be financed entirely by 
bond sales; however, a constant positive deficit inclusive of interest payments can. Although most studies take this approach, Trehan and Walsh (1988) show that the IGBC implies that government expenditure inclusive of interest, tax receipts and seigniorage be cointegrated. However, the condition is in fact stronger, requiring that the deficit inclusive of interest be stationary.

Although many studies support the sustainability of government debt, the results are controversial. For the periods 1960-1981 and 1890-1986 Hamilton and Flavin (1986) and Trehan and Walsh (1988), respectively, found that US data was consistent with the IGBC. Hakkio and Rush (1991) examined US data for the period 1950-1988 and found that revenue and government spending were cointegrated. However, when they restricted the analysis to the period 1968-1988, they found that the series were no longer cointegrated and then the government changed is policy on debt solvency. Wickens and Uctum (1993) took a different approach analysing the issue in terms of balance of payments identity solved forward. The framework allows for endogenous rather than exogenous primary deficit. The sufficient condition to satisfy the IGBC is that the largest absolute root in the VAR be less than one plus the real exchange rate adjusted for output growth. The consequence is that the trade deficit exhibits a wealth effect, so that net national indebtedness increases and there is an improvement in the trade deficit. Then, higher government debt reduces the primary deficit. This occurs if government debt is regarded by the private sector as net wealth. Using US data for the period 1970-1988, they found that despite a large current account deficit, the loss of national wealth acted as an automatic corrective, enabling the US to avoid defaulting. Since the time spans of the latter two studies are quite short, we believe that they are not suitable for time-series analysis and then that these results are not conclusive. 
Bohn (1998) argued that wartime and cyclic fluctuations can obscure the relationship between primary surplus and debt. Therefore, univariate regression of the first on the second would not detect a significant correlation between the two: even if it is impossible to reject a unit root, this test leads to inconsistent and misleading results. For 1916-1995 he found that the primary surplus was an increasing function of the debt-toGDP ratio. In addition, when one controls for wartime and cyclic fluctuations, an autoregressive model shows that the debt-to-GDP ratio is mean-reverting. Under weak conditions, a positive (at least linear) response of primary surpluses to the debt-to-GDP ratio implies that the IGBC is satisfied.

In a number of more recent papers, the stability of the IGBC is tested in face of possible changes in fiscal policy. Using US data from 1947(2) to 1992(3), Quintos (1995) found a major breakpoint in 1980(4). weak sustainability for the overall period by applying the Hansen parameter stability test. She showed that revenues and expenditure inclusive of interest are cointegrated in the pre-break period, but are not cointegrated in the post-break period. The evidence supports strong sustainability in the pre-break periods, but only weak sustainability ${ }^{1}$ in the post-break period. Martin (2000) applied an integrated cointegration/structural methodology, allowing for multiple shifts in level and slope parameters. The inferential approach is Bayesian, with rests based on Markow chain Monte Carlo posterior simulators. Strong long-run sustainability was found, with three breaks endogenously determined in the first quarters of 1975, 1985, and 1987, over the

\footnotetext{
${ }^{1}$ Strong sustainability means that the IGBC holds, and the undiscounted debt process $B_{t}$, is $I(1)$. Weak sustainability means that the constraint holds, but that $B_{t}$ is exploding at a rate lower than the growth rate of the economy. This situation is consistent with sustainability, but may turn into a default situation.
} 
same time-span used as in Quintos. However, these changes were small and almost offset each other, implying fulfilment of the IGBC over the whole period. ${ }^{2}$

Leachman (1996) jointly tested for the IGBC and the consumers' budget constraint in testing for Ricardian equivalence. Changes in government spending and tax revenue were cointegrated and changes in tax receipts and debt were not. This meant that fiscal variables were not multicointegrated. ${ }^{3}$ Thus, it does not exist a deeper level of cointegration between government spending and taxes, as would be expected if the government fulfils the IGBC. Explorative work aiming at characterizing fiscal policy in terms of non-linearity has been recently undertaken. Manasse (1996) modelled government expenditure as a regulated Brownian motion (a random process with an upper bound) finding linear cointegration between taxes, government spending and debt for nine OECD countries, while Canada and the US showed a non-linear cointegration between these variables as defined by Granger and Hallman (1991). ${ }^{4}$ The interpretation was that unsustainable policies are in fact consistent with optimising behaviour when future stabilization is accounted for. Giavazzi et al. (2000) noted that governments react more to primary deficits (surpluses) when public debt is particularly high (low), which implies a non-linear relationship between surplus and debt, and in the debt-to-GDP ratio. Using an Exponential Smooth Transition Autoregressive (ESTAR) model, Sarno (2001) found that the US debt-to-GDP process is a non-linear mean-reverting stochastic process over the period 1916-1995. This implies that the IGBC was fulfilled.

\footnotetext{
${ }^{2}$ Similar results are obtained by Haug (1995), with respect to policy changes during the Reagan and Bush administrations.

${ }^{3}$ If the two series are $I(1)$, have no trend and cointegrated such that a linear combination of them, $z_{t}$, is $I(0)$, then it follows that: $Q_{t}=\sum_{j=0}^{t} z_{t-j}$, where $q_{t}$ will be $I(1)$. If $q_{t}$ and $x_{t}$ are cointegrated, then $x_{t}$ and $y_{t}$ will be multicointegrated and $q_{t}$ and $y_{t}$ will also be cointegrated. Since $q_{t}$ is a function of $x_{t}, y_{t}$ and their lags, multicointegration implies long run relationships at two different levels between just two series.

${ }^{4}$ This relationship was found over the periods $1961-93$ and 1963-9, respectively.
} 


\section{Empirical methodology and data}

The first stage of this work is to establish whether the series are non-linear trend stationary. This is done in two ways: first we apply a battery of tests in which the unit root hypothesis is either the null or the alternative, tested against stationarity or trend stationarity, as appropriate. Conflicting results of these tests may be interpreted as the possibility of the series being stationary around a non-linear deterministic trend. Next we apply four tests developed by Bierens (1997) in which the null of a unit root with drift process is tested against non-linear trend stationarity. After the data generating process has been assessed and specified in terms of non-linear trend stationarity, we implement the Bierens (2000) co-trending test.

Bierens (1997) proposes a group of tests based on the Dickey-Fuller model augmented with orthogonal Chebishev polynomials:

$$
\Delta z_{t}=\alpha z_{t-1}+\sum_{i=1}^{p} \phi_{i} \Delta z_{t-i}+\sum_{j=0}^{m} \theta_{j} P_{j, t}+\varepsilon_{t}
$$

where $P_{0, t}$ to $P_{m, t}$ are Chebishev polynomials, $P_{0, t}$ equals $1, P_{1, t}$ is equivalent to a linear trend, and $P_{2, t}$ through $P_{m, t}$ are cosine functions. ${ }^{5}$ We use four tests from this model:

1. $\hat{t}(m)$, the t-statistic on the estimated coefficient $\hat{\alpha}$;

\footnotetext{
${ }^{5}$ Ouliaris et al. (1989) discuss the use of ordinary time polynomials in the augmented Dickey-Fuller test. Inclusion of a time polynomial of order $m$ allows for power against a deterministic trend of order $m$, while controlling for non-linear drift of order $m-1$ under the null. The use of the Chebishev polynomials allows for distinguishing between linear and non-linear trend under the alternative hypothesis, because the orthogonality and the closed form make it possible to approximate highly non-linear trends.
} 
2. $\hat{A}(m)=n \hat{\alpha} / 1-\sum_{i=1}^{p} \hat{\phi}_{i} \mid{ }^{6}$

3. $\hat{F}(m)$, joint $\mathrm{F}$ test on $\hat{\alpha}$ and coefficients of non-constant Chebishev polynomials;

4. $\tilde{T}(m)$, nonparametric joint test on $\hat{\alpha}$ and the coefficients of non-linear Chebishev polynomials.

The null of these tests is unit root with drift, while the alternative is linear or nonlinear deterministic trend stationarity. In particular, left-side rejections for the $\hat{t}(m), \hat{A}(m)$ and $\tilde{T}(m)$ tests indicate non-linear trend stationarity, whereas right-side rejections are ambiguous, since the process can be mean stationary, trend stationary or non-linear trend stationary. In the latter test, the non-linear trend stationary hypothesis is not contemplated. The $\hat{F}(m)$ test is one sided and right-side rejections lead to the above ambiguous result for the two tests. According to Cushman (2002), this ambiguity can be solved in favour of non-linear trend stationarity when rejections occur only at non-linear orders, since the non-linear trend might not be detected if the deterministic parts were not correctly specified, having a too low time order.

Once we have determined that the series are stationary around a non-linear trend, we can investigate whether they have non-linear trends in common. Bierens (2000) develops a test similar to the search for common stochastic trends and cointegration for unit root series, a relationship called non-linear co-trending. The test is based on the eigenvalues of matrices constructed from partial sum of the variables. It is nonparametric since the nonlinear trends and serial correlation processes do not need to be specified. The test statistic is $\lambda_{r}$ for $r=1$ through $k$, where $r$ is the number of co-trending vectors under the null, and $k$

\footnotetext{
${ }^{6}$ Bierens (1997) specifies this test without taking the absolute value. This modification is made in Bierens (2002) because, under $\mathrm{H}_{1}, \hat{\phi}$ can be negative.
} 
is the number of variables. The alternative hypothesis is that there are $r-1$ co-trending vectors. The test procedure also gives estimates for the co-trending vector parameters. Let $y_{t}$ denote a demeaned and de-linear-trended vector of variables, and define:

$$
\hat{M}_{1}=(1 / n) \sum_{t=1}^{n} \hat{F}(t / n) \hat{F}(t / n)^{T}
$$

where $\hat{F}(x)=(1 / n) \sum_{t=1}^{n x} y_{t}$ if $x \in\left[n^{-1}, 1\right], \hat{F}(x)=0$ if $x \in\left[0, n^{-1}\right]$, and

$$
\hat{M}_{2}=(1 / n) \sum_{j=s}^{n}\left((1 / s) \sum_{j=0}^{s-1} y_{t-j}\right) \times\left((1 / s) \sum_{j=0}^{s-1} y_{t-j}\right)^{T}
$$

Then solve:

$$
\left|\hat{M}_{1}-\lambda \hat{M}_{2}\right|=0
$$

Taking the ordered solutions of (7), the test statistics are calculated as $n^{1-\alpha} \hat{\lambda}_{r}{ }^{7}$ Bierens (2000) gives the asymptotic critical values for this test, but since they suffer from size distortion, the p-values are simulated by estimating 1000 replications of a Gaussian $\operatorname{AR}(p)$ process for the variable to be tested with the estimated parameters, using the first $p+1$ observations (determined by the Akaike Information Criterion, AIC) to initialise.

This analysis is applied to Italian annual data from 1861 to 1998. Expenditure is defined as the sum of total budget outlays less interest payments on debt, calculated as a ratio to GDP. The average tax rate is the ratio of government revenue to GDP. All data is in nominal terms. Data for GDP, debt, interest payment on outstanding debt are from Fratianni and Spinelli (2001). Government expenditure and taxes are from Spinelli and Fratianni (1991) for the period 1861-1980, and from Istat (various years) for the remaining 
period. Figure 1 shows data for these variables and government debt, which is from the same sources.

[Figure 1 about here]

\section{Empirical results}

In this Section we present the results of our estimations. We first introduce the results of several unit root and stationarity tests, where in some cases the null is the nonstationarity hypothesis against the stationarity one, and vice versa in other cases. Conflicting results in these tests are the first evidence of non-linear trend stationarity. We then apply a battery of non-linear trend stationarity tests. Having shown that the series are non-linear trend stationary, we then test for the existence of common long-run behaviour between government expenditure and taxes. Finally, the dynamic effects of government spending on government debt are traced out both in a linear and a non-linear framework.

\subsection{Unit root and stationarity tests}

The first stage in our estimation strategy is to assess the nature of the data generating process of the series involved. A battery of unit root and stationarity tests is therefore used on data in levels and first-differences. This is done because failure to reject the null hypothesis does not mean to accept it, therefore it is wise to consider these tests where the null hypothesis in one (unit root) is the alternative in the other (stationarity), and vice versa. The first pair of tests is the Augmented Dickey-Fuller: in the first the null hypothesis of unit root is tested against stationarity, in the second it is tested against trend

\footnotetext{
${ }^{7} \mathrm{~s}$, the order of nonparametric serial correlation correction is equal to $n^{\alpha}$, with $\alpha=0.05$ which is the rate of
} 
stationarity. The default lag-length is determined as $p=c n^{r}$, where $c=5$ and $r=0.25$. A series of Wald tests is used to determine the actual lag-length. The second pair of tests is the Phillips-Perron (1988): in the first the null of unit root is tested against stationarity, while in the second the null of unit root with drift is tested against trend stationarity. These tests employ a Newey-West (1987) type variance estimator of the long-run variance of $u(t)$ with truncation lag determined setting $k=c n^{r}$, with $c=5$ and $r=0.25$. The following tests are the Bierens (1993) unit root tests on the basis of higher-order sample autocorrelations. The first two are tested against stationarity, and the other two against linear trend stationarity. The lag-length is determined according to $k=1+\left[\alpha n^{\delta \mu /(3 \mu+2)}\right]$, where $\mu=2, \alpha=5$, and $\delta=0.5$. Critical values reported in Table 1 are based on asymptotical distributions. The last two unit root tests are nonparametric (Breitung, 2002). In the first the alternative hypothesis is stationarity, in the second the null of unit root with drift is tested against trend stationarity. ${ }^{8}$

The last eight tests have stationarity as null hypothesis and unit root as alternative. In particular, the first four Bierens and Guo (1993) Cauchy tests directly test this hypothesis, while the $5^{\text {th }}$ and the $6^{\text {th }}$ tests assume trend stationarity as null and unit root with drift as alternative. The Bierens-Guo test 4 employs a Newey-West type variance estimator of the long run variance of $u(t)$, with truncation lag $m=c n^{r}$ with $c=5$ and $r=$ 0.25. The last two tests are KPSS (Kwiatkowsky et al., 1992). The first tests the null of

convergence of the partial sum that embodies the serial correlation correction.

${ }^{8}$ Let $y(t), t=1, \ldots, n$, be a unit root process: $y(t)=y_{t-1}+u_{t}$, where $u_{t}$ is a zero-mean stationary process. Compute the partial sums $Y(t)=y_{1}+y_{2}+\ldots .+y_{t}$, and then the ratio

$B(n)=\frac{\left[Y_{1}^{2}+Y_{2}^{2}+\ldots+Y_{n}^{2}\right] /\left(n^{2}\right)}{\left[y_{1}^{2}+y_{2}^{2}+\ldots+y_{n}^{2}\right] / n}$.

Under the unit root hypothesis $B(n) / n$ converges in distribution to a function of a standard Wiener process, which is free of nuisance parameters. On the other hand, if $y(t)$ is stationary then $B(n)$ itself converges in distribution, hence $B(n) / n$ converges in probability to zero. If the alternative hypothesis is that $y(t)$ is stationary with a non-zero mean, then $y(t)$ is first demeaned, and if the alternative is that $y(t)$ is trend stationary, then $y(t)$ is first detrended. 
stationarity against the alternative of unit root, and the second tests trend stationarity against the unit root with drift hypothesis. The KPSS test employs a Newey-West type variance estimator of the long-run variance of $u(t)$, with truncation lag $m=\mathrm{cn}^{r}$, where $c=$ $5, r=0.25$.

Table 1 reports the results for government expenditure and taxes. In both cases they are rather inconclusive, especially for the latter. In particular, the two ADF tests yield mixed results, whereas the Phillips-Perron tests are unable to reject the unit root hypothesis, but at $10 \%$ significance level only. The tests based on higher-order sample autocorrelations $(\operatorname{HOAC}(1,1)$ and $(2,2)$, DHOAC $(1,1)$ and $(2,2))$ are consistent in rejecting the unit root hypothesis. The nonparametric tests (Breitung 1 and 2) lead to opposite results, the first accepting and the second not accepting the unit root. Stationarity tests are contradictory: the first two Bierens-Guo tests reject the stationarity hypothesis, while the other four accept it. One KPSS test does not accept stationarity, while the other accept it.

For taxes the picture is similar, though less conflicting. The ADF and PP tests do not reject the null hypothesis of unit root, but the positive values of the ADF1 and PP1 are unusual and further analysis is therefore needed. The two HOAC tests are less favourable to the null, since the first does not accept it at the conventional significance levels, and the same happens for the second at the $10 \%$ level. In contrast, the DHOAC tests - as well as the two nonparametric tests - do not reject the unit root hypothesis. For stationarity tests, all but BG6 and KPSS2 reject the null.

[Table 1 about here] 


\subsection{Non-linear trend stationarity tests}

When implementing the Bierens non-linear trend stationarity test, one faces the decision to determine $p$, the order of lagged first difference of the stochastic part of the time series, and $m$, the order of the Chebishev time polynomials. One can use different criteria in determining $p$, for example the AIC or the sequential test proposed by $\mathrm{Ng}$ and Perron (1995). We opted for the former method, which is more appropriate for simulating the actual value of the test size, though the other results in lower size distortion. The issue of ascertaining $m$ is more difficult, since there is no explicit criterion to determine it, and the power and the actual size of the test depend on $m$. If $m$ is chosen too low, a non-linear trend may not be detected, which amounts to lack of power. If $m$ is too superfluous parameters may be estimated, which in turn may cause lack of power. Nonetheless, the tests show substantial size distortion, their assessment has to be done by simulating pvalues by estimating an autoregressive first difference model (with lag order determined by AIC). Using the estimated parameters and sampling from the rescaled residuals of the estimated model, 1000 new first difference series were generated, using the first $p+1$ actual values to initialise. Errors were drawn from the normal distribution with zero mean and variances the squared OLS residuals. This wild bootstrapping method was used to take into account heteroskedasticity that was found estimating the model. The Chebishev polynomial was set equal to 10 and then estimation was performed. Since the variable $T A X$ shows evidence of non-linear trend stationarity at this order, the results are presented. This is not the case of $G O V$, where it is necessary to set $m=20$ to obtain results consistent 
with non-linear trend stationarity. ${ }^{9}$ This may be due to a lack of smoothness of the nonlinear trends.

For government spending (Table 2) the $t$ test and the $\hat{A}_{m}$ test reject the null at the $10 \%$ level on the left side, a result confirmed by the relevant simulated p-values. Unfortunately this outcome does not tell us whether stationarity is around a mean, linear trend, or non-linear trend. Estimating the model at linear orders ${ }^{10}$ yields a right-side rejection, since the test statistics are -3.4680 and -27.8467 , respectively. However, the simulated p-values for this test were 0.1420 and 0.1220 , which do not enable us to reject the null of unit root with drift. Therefore rejection of the null is only obtained at the nonlinear order, leading to the non-linear trend stationarity alternative hypothesis (Cushman, 2002). The $\hat{F}_{m}$ test does not reject the unit root with drift hypothesis, whereas the $\tilde{T}$ test leads to non-linear trend stationarity because of right-side rejection, but this is misleading since considerable size distortion was detected by the small sample pre-test.

[Table 2 about here]

For the TAX variable the picture is simpler. The first two tests reject the unit root with drift hypothesis at the $10 \%$ significance level, in favour of non-linear trend stationarity because we have two right-sided rejections. The other two tests are unable to reject the null. These results are confirmed by small sample pre-tests (Table 3).

[Table 3 about here]

\footnotetext{
${ }^{9}$ Results for the polynomial of order 10 are available from the author.

${ }^{10}$ At linear orders the model is estimated with $m=1$, which means that we include an intercept and a linear time trend. Results, available from the author, are similar for $m=0$ (only intercept).
} 
Taken together with those in the previous Subsection, these results overall suggest non-linear trend stationarity for both variables. Figures 2 and 3 show the fit of the model for government expenditure and taxes, respectively. ${ }^{11}$ The autoregressive part of the model (p) was set equal to 1 for $T A X$ and 2 for GOV, according to the AIC, and a Chebishev polynomial $(m)$ of order 10 was added to capture non-linearity for TAX, and of order 20 for $G O V$.

[Figures 2 and 3 about here]

\subsection{Co-trending tests}

Now we turn to the non-linear co-trending test. The parameter $\alpha$ was set equal to 0.5 , and the test was conducted on the demeaned variables, because they do not show a clear trending pattern. ${ }^{12}$ The ordered generalized eigenvalues of $\hat{M}_{1}$ with respect to $\hat{M}_{2}$ were $\hat{\lambda}_{1}=0.1391496$ and $\hat{\lambda}_{2}=0.09644432$, and the corresponding generalized eigenvectors of $\hat{M}_{1}$ with respect to $\hat{M}_{2}$ were:

$$
\begin{array}{lr}
1-0.85035 & \leftarrow \mathrm{GOV} \\
0.22702 & 1 \leftarrow \mathrm{TAX}
\end{array}
$$

When the hypothesis of $r$ co-trending vectors was tested against the alternative of $r$ - 1 cotrending vectors, yielded the results summarized in Table 7, which tells us that there exists

\footnotetext{
${ }^{11}$ Note that in these figures the values of the variables are standardised, whereas in Figure 1 they are the actual values.
} 
one co-trending vector. This standardised vector $\mathrm{H}=(-0.8329,1)$ was determined according to a $\lambda$-max test statistic equal to 0.16 with $10 \%$ and $5 \%$ critical values respectively equal to 0.352 and 0.466 , under the null hypothesis that there exists a cotrending vector $x$ satisfying $x=H y$, where $y$ is an arbitrary conformable vector.

We can write $F(x)=Q_{2} Q_{2}{ }^{\prime} F(x)$, where $Q_{2}$ is the matrix of orthogonal eigenvectors of $\hat{M}_{1}$ corresponding to the positive eigenvalues. The vector $Q_{2}^{\prime} F(x)$ can be interpreted as the vector of common cumulative non-linear trends. Similarly, $F^{\prime}(x)=Q_{2} Q_{2}{ }^{\prime} F^{\prime}(x)$, where $Q_{2}$ is the matrix of orthogonal eigenvectors of $\hat{M}_{2}$ corresponding to the positive eigenvalues. The vector $Q_{2}^{\prime} F^{\prime}(x)$ can be interpreted as the vector of common non-linear trends. ${ }^{13}$ Therefore we obtain:

Common cumulative non-linear trend $=$

0.76839 x Component of $F(x)$ corresponding to GOV

$+0.63998 \times$ Component of $F(x)$ corresponding to TAX

Cumulative non-linear trend in GOV $=$

0.768391x Common cumulative non-linear trend

Cumulative non-linear trend in TAX $=$

$0.63998 \times$ Common cumulative non-linear trend

Common non-linear trend $=$

$0.80701 \times$ x Component of $F^{\prime}(x)$ corresponding to GOV

$+0.59054 \times$ Component of $F^{\prime}(x)$ corresponding to TAX

Non-linear trend in GOV $=0.80701 \times$ Common non-linear trend

Non-linear trend in TAX $=0.59054 \times$ Common non-linear trend.

\footnotetext{
${ }^{12}$ Results for detrended data are similar in terms of the number of cointegrating vectors, but less in line in terms of the pattern of the nonlinear common trend. They are available upon request from the author.

${ }^{13}$ These decompositions are not included in Bierens (2000), but are available in Bierens (2002).
} 
Figure 4 plots the estimated $F(x)$ and $F^{\prime}(x)$ components for both $G O V$ and $T A X$, standardised between -1 and 1. They appear rather synchronised, confirming that government receipts and outlays are linked via a common non-linear trend.

[Figure 4 about here]

\subsection{VAR estimates}

The dynamic relationships between government expenditure and government debt may be studied in a VAR framework, tracing out the impulse response functions derived from unexpected shocks on the variables of interest (Figure 5). ${ }^{14}$ We estimated a nonstructural VAR (Sims, 1980) with six lags, as suggested by the AIC, with intercept and trend. To capture possible data heterogeneity we added a non-linear time trend, which is a Chebishev time polynomial of order 10 . The test for joint significance of the detrended Chebishev polynomial rejects the null hypothesis that its coefficients are all equal to zero at the 5\% significance level, since the Wald test is equal to 33.03 and the $5 \%$ critical value is 18.31. Dots represent plus and minus one and two standard errors bands. The time-span was set at ten years. Inspection of the four panels reveals a substantial confirmation of the above results. In ten years time, the variables absorb almost completely the shocks hitting them. Debt is sticky and takes some time to deviate from its original level. It reaches a maximum in the $6^{\text {th }}$ year after the shock, and then declines to the original level. This is the only case in which a shock appears to last longer, still without permanent effects. A shock of government expenditure on itself lasts about four years, then tends to a level lower than the starting one. Note that this is consistent with optimal taxation over time because the

\footnotetext{
${ }^{14}$ For government debt we have carried out the same tests applied to the two other series, reaching the same qualitative results. Details are available upon request from the author.
} 
government starts to accumulate a budget surplus to pay back the increased debt. A shock on debt has a zero effect on government expenditure ${ }^{15}$ since the zero line is always included in the estimation deviations. A shock on debt on itself lasts about four years and then there is a small tendency to return to the original level.

It is interesting to compare these results with those obtained without taking out the non-linear trend (Figure 6). In this case the results change at least qualitatively. A shock on government expenditure on itself tends to last longer, it is bigger than in the previous case and does not tend to fall below the initial value. A shock of debt on itself seems to have permanent effects, while the effects of a shock on government expenditure on debt does not appear to be permanent, but tend to last much more than before. In the remaining case there are no significant effects.

[Figures 5 and 6 about here]

\section{Conclusions}

In this paper we have addressed the issue of the intertemporal government budget constraint applying the notions of non-linear trend stationarity and non-linear co-trending for the two time series involved in this framework: government outlays and receipts. We found that the two series can be represented by non-linear trend stationarity instead of unit root processes, and that a non-linear long-run relationship does exist between them, fulfilling fiscal sustainability. From an economic point of view, it makes sense to think that policy makers (those responsible for fiscal decisions over the long period analysed

\footnotetext{
${ }^{15}$ Recall that this measure of government expenditure excludes interests on debt.
} 
here) might have acted as if they were guided by specific rules (e.g., do not accumulate too much government debt) in responding to stochastic fiscal shocks. As long as these shocks are stochastic, we can figure out that responses were stochastic signals too. From time to time there were presumably different attitudes to respond to fiscal signals, because fiscal authorities do change over time. Therefore, the non-linear trend relationships uncovered here constitute a mixture of stochastic and deterministic components in the making of fiscal policy. 


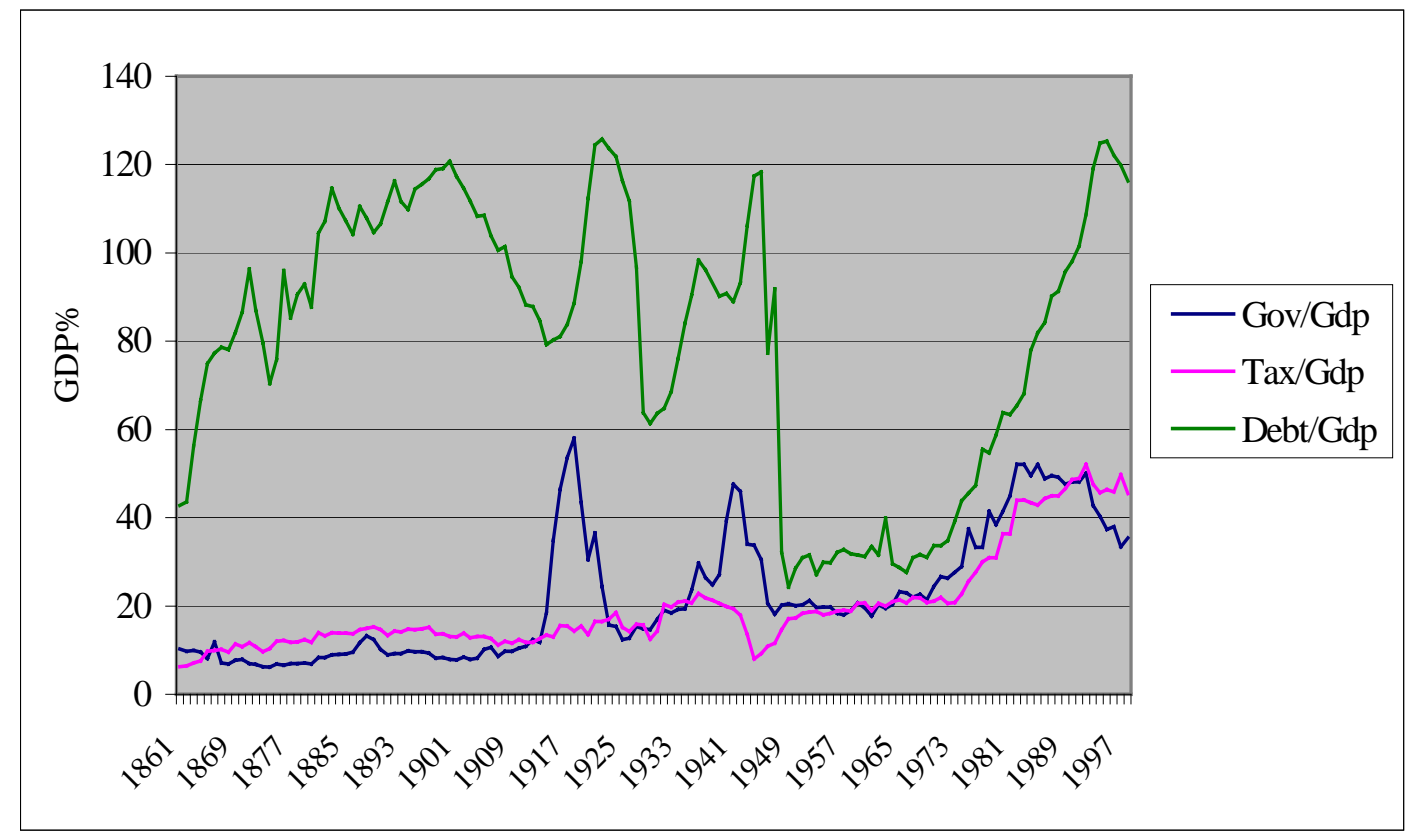

Figure 1 - Italian fiscal aggregates 
Solid line: GOV

Dotted line: OLS model
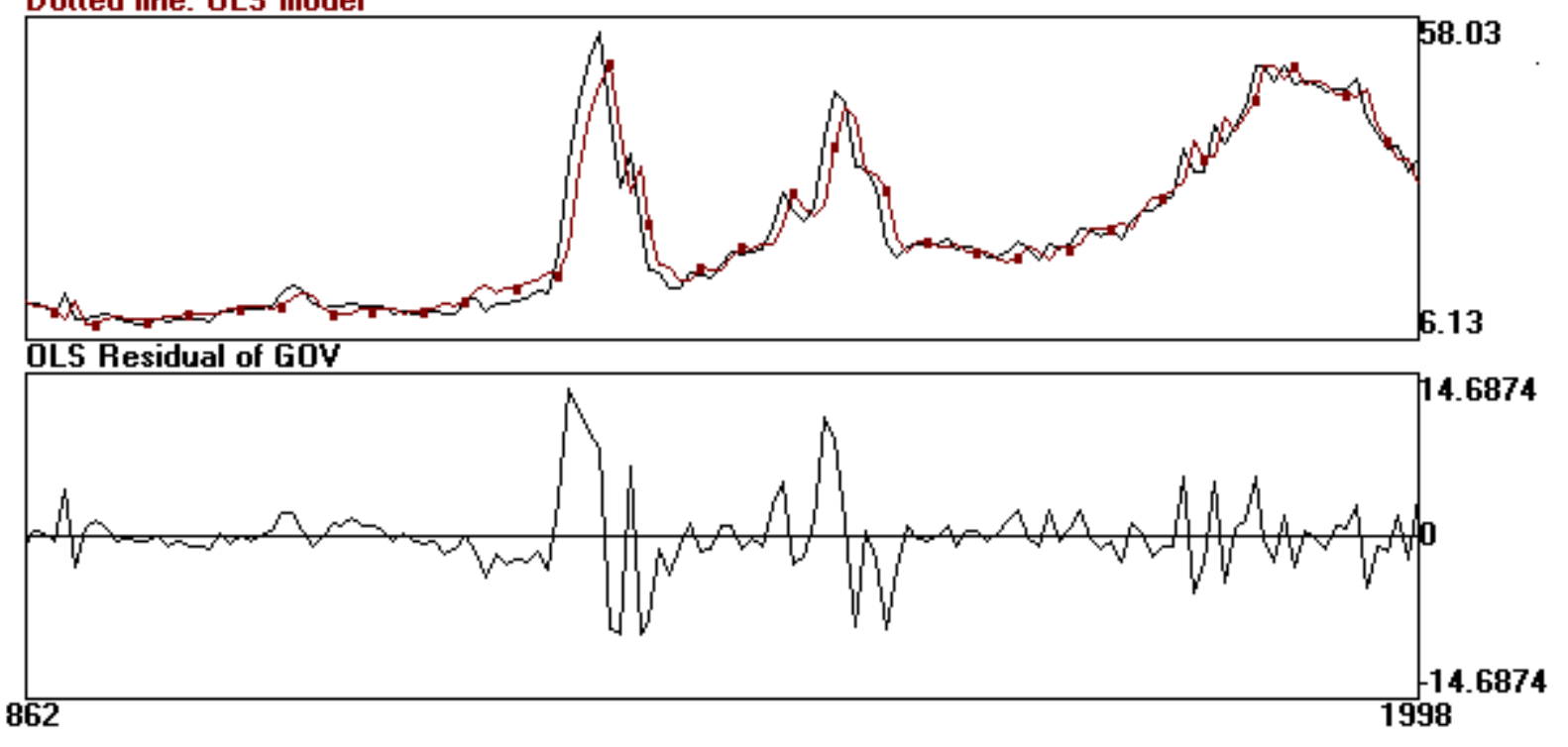

Figure 2 - Fit of the non-linear model and residuals for government expenditure

Solid line: TAX

Dotted line: OLS model

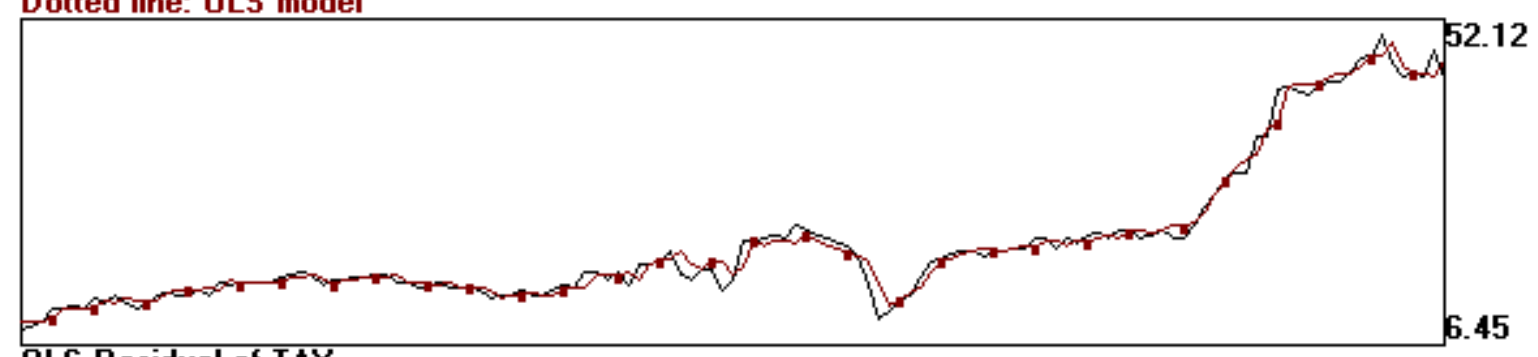

OLS Residual of TAX

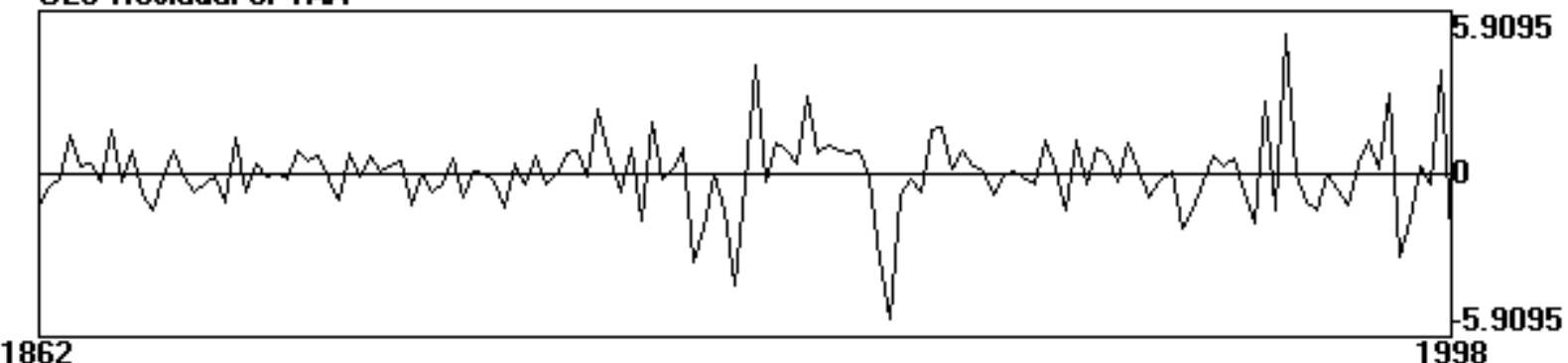

Figure 3 - Fit of the non-linear model and residuals for taxes 

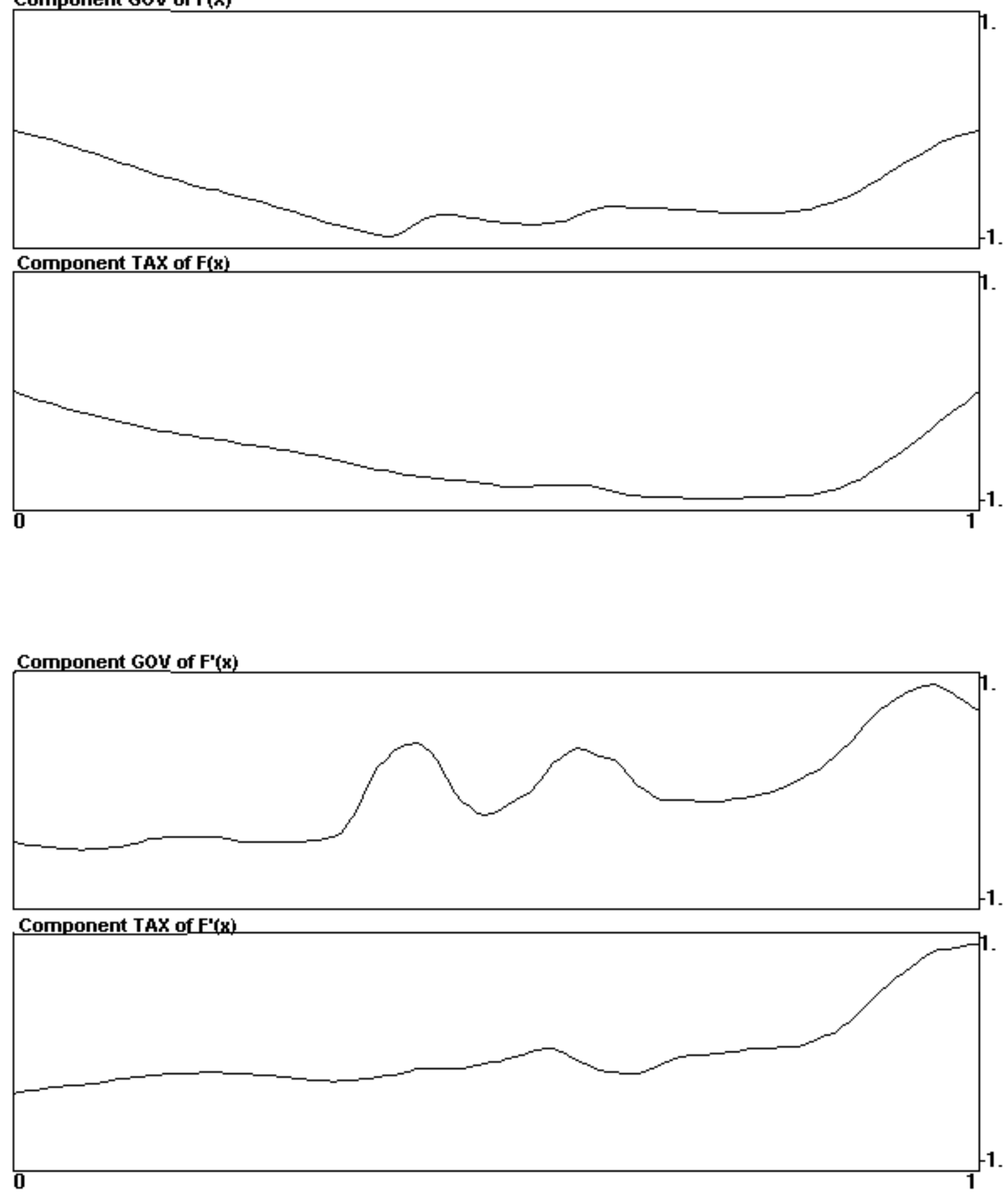

Figure 4 - Estimated F(x) and F'(x) components for GOV and TAX 
Response of DEBT to a unit shock in GOV

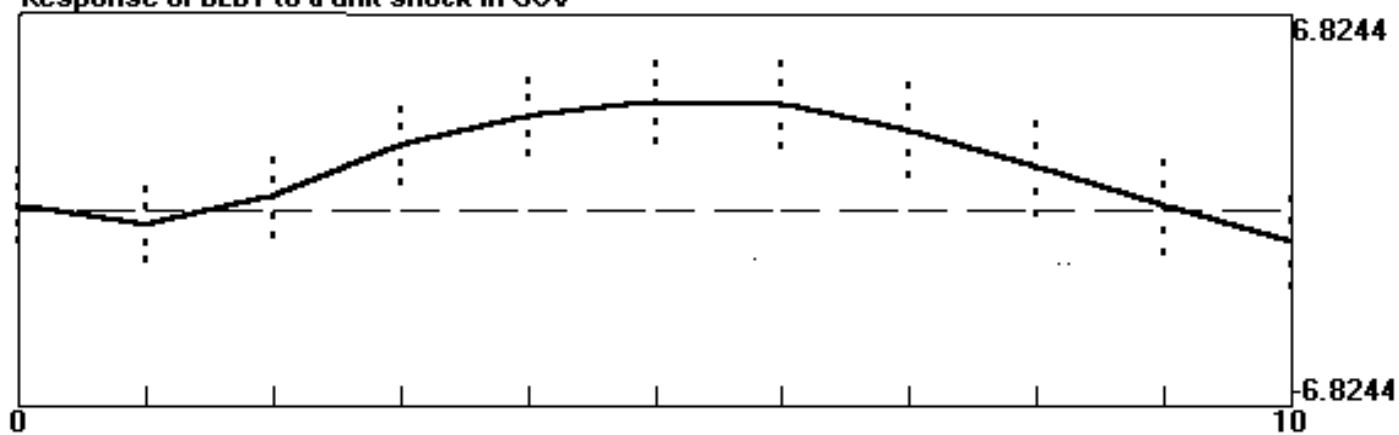

Response of GOV to a unit shock in GOV

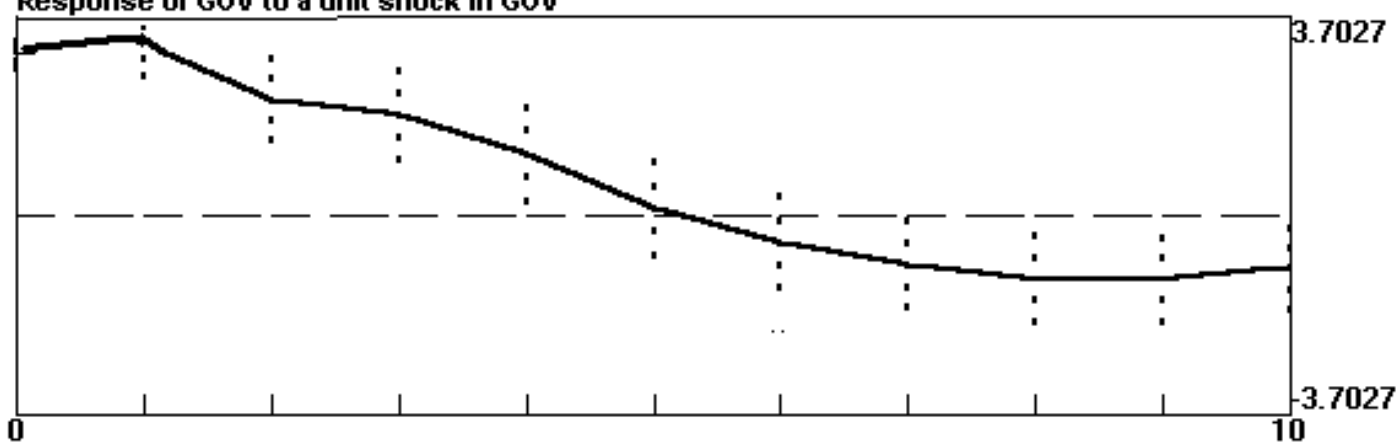

Response of DEBT to a unit shock in DEBT
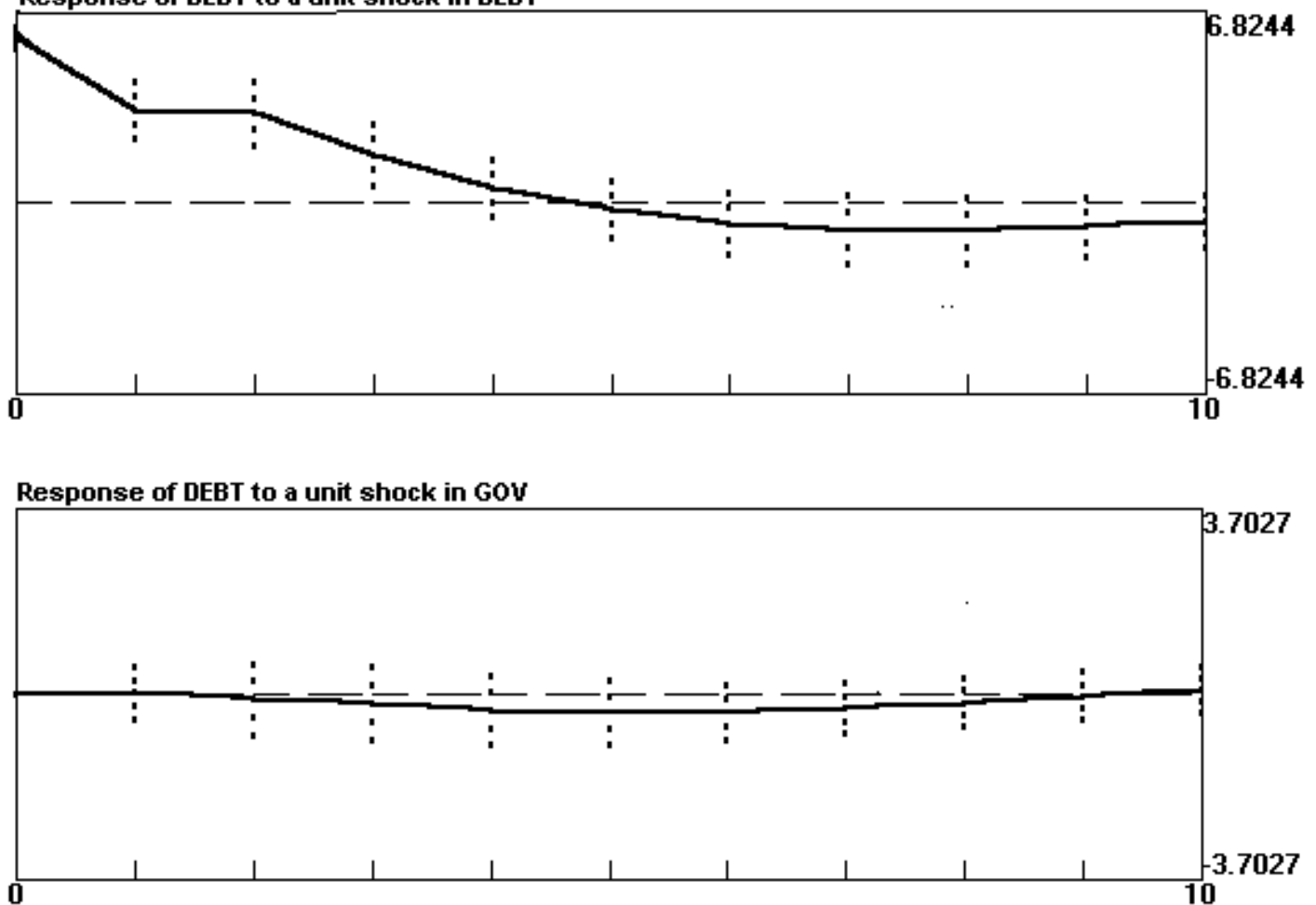

Figure 5 - Impulse response functions of the VAR between government expenditure and government debt, taking out the non-linear trend 

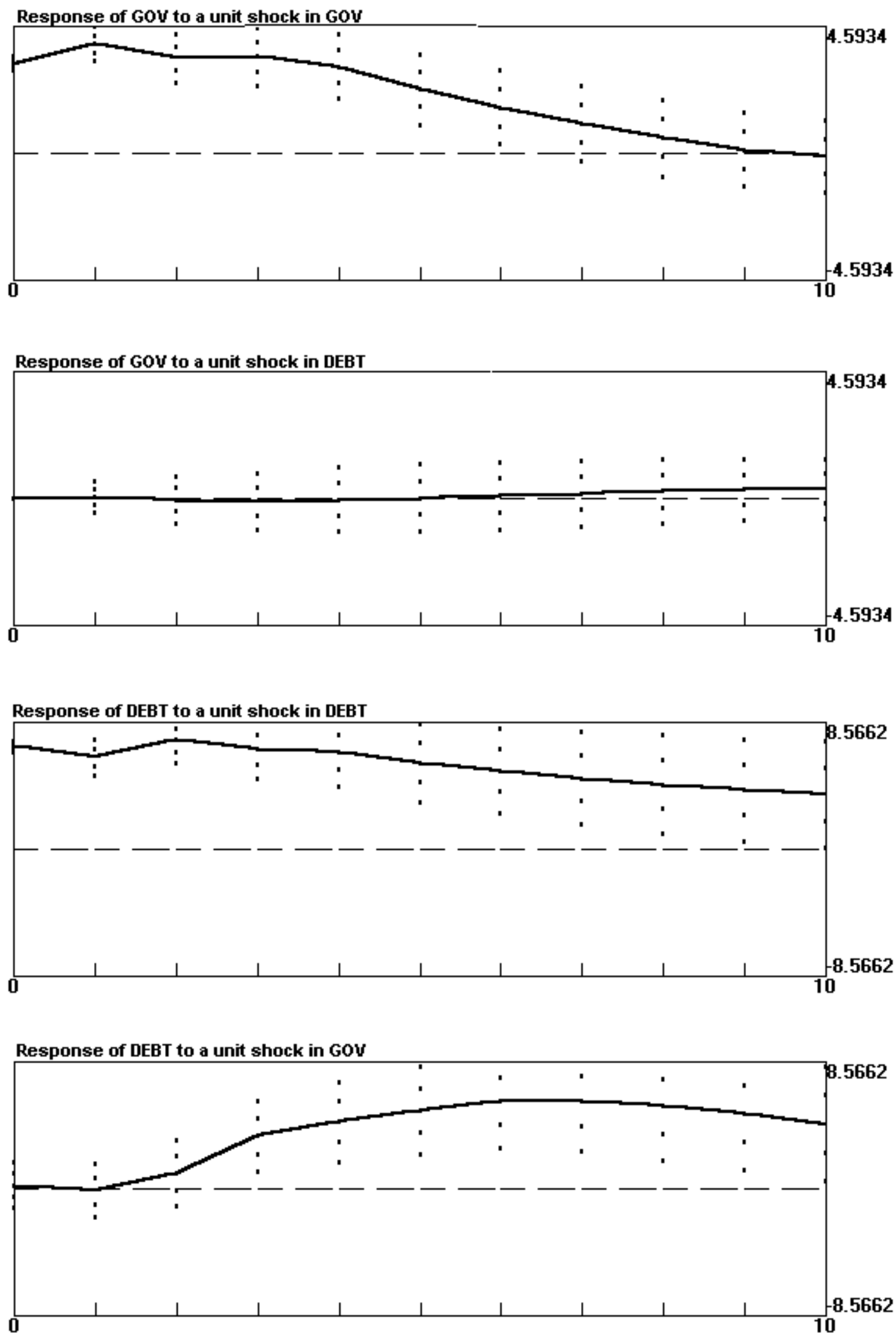

Figure 6 - Impulse response functions of the VAR between government expenditure and government debt, without taking out the non-linear trend 
Table 1 - Unit root and stationarity tests for government expenditure and taxes

\begin{tabular}{lrrrrrr}
\hline Test & \multicolumn{2}{c}{ Test statistics } & \multicolumn{2}{c}{ Critical regions } & $\mathrm{H}_{0}$ & $\mathrm{H}_{1}$ \\
& GOV & TAX & $5 \%$ & $10 \%$ & & \\
\hline ADF1 & -2.2307 & 0.9208 & $<-2.89$ & $<-2.58$ & UR & ST \\
ADF2 & -3.5908 & -0.4955 & $<-3.40$ & $<-3.13$ & UR & TS \\
PP1 & -5.46 & 0.17 & $<-14.51$ & $<-11.65$ & UR & ST \\
PP2 & -12.43 & -4.29 & $<-21.78$ & $<-18.42$ & URD & TS \\
HOAC(1,1) & -19.94 & -19044.00 & $<-14.00$ & $<-11.20$ & UR & ST \\
HOAC(2,2) & -19.75 & -14.25 & $<-15.70$ & $<-13.10$ & UR & ST \\
DHOAC(1,1) & -87.30 & -1.42 & $<-20.60$ & $<-17.10$ & URD & TS \\
DHOAC(2,2) & -102.23 & -26.72 & $<-22.40$ & $<-18.90$ & URD & TS \\
B1 & 0.05731 & 0.06512 & $<0.01004$ & $<0.01434$ & UR & ST \\
B2 & 0.00255 & 0.01505 & $<0.00343$ & $<0.00438$ & URD & TS \\
BG1 & 14.3194 & 118.5222 & $>12.71$ & $>6.31$ & ST & UR \\
BG2 & 14.8228 & 137.9928 & $>12.71$ & $>6.31$ & ST & UR \\
BG3 & 4.2829 & 14.9687 & $>12.71$ & $>6.31$ & ST & UR \\
BG4 & 4.2484 & 14.0863 & $>12.71$ & $>6.31$ & ST & UR \\
BG5 & 1.4413 & 31.9796 & $>12.71$ & $>6.31$ & TS & URD \\
BG6 & 1.499 & 3.7215 & $>12.71$ & $>6.31$ & TS & URD \\
KPSS1 & 0.6816 & 0.6653 & $>0.46$ & $>0.35$ & ST & UR \\
KPSS2 & 0.0638 & 0.1082 & $>0.15$ & $>0.12$ & TS & URD \\
\hline
\end{tabular}

ST: stationary, TS: trend stationary, UR: unit root, URD: unit root with drift. 
Table 2 - Tests of the unit root with drift hypothesis against non-linear trend stationarity for GOV

\begin{tabular}{lrrrrrr}
\hline Test & $\begin{array}{r}\text { Test } \\
\text { statistics }\end{array}$ & \multicolumn{3}{c}{ Fractiles of the asymptotic null distribution } & $\begin{array}{r}\text { Simulated } \\
\text { p-values }\end{array}$ \\
\cline { 3 - 5 } & & 0.05 & 0.10 & 0.90 & 0.95 & \\
\hline$\hat{t}(m)$ & -6.1382 & -6.98 & -6.29 & -4.17 & -3.58 & 0.9360 \\
$\hat{A}(m)$ & -147.0636 & -87.00 & -73.70 & -36.60 & -29.60 & 0.9420 \\
$\hat{F}(m)$ & 3.4795 & & & 4.60 & 5.53 & 0.0310 \\
$\tilde{T}(m)$ & 3541.815 & 223.45 & 369.51 & 1408.65 & 1930.47 & 0.3790 \\
\hline
\end{tabular}

Fractiles shown are the appropriate values for both one- and two-sided tests.

Table 3 - Tests of the unit root with drift hypothesis against non-linear trend stationarity for TAX

\begin{tabular}{lrrrrrr}
\hline Test & $\begin{array}{r}\text { Test } \\
\text { statistics }\end{array}$ & \multicolumn{2}{c}{ Fractiles of the asymptotic null distribution } & $\begin{array}{r}\text { Simulated } \\
\text { p-values }\end{array}$ \\
\cline { 3 - 5 } & & 0.05 & 0.10 & 0.90 & 0.95 & \\
\hline$\hat{t}(m)$ & -3.765 & -6.98 & -6.29 & -4.17 & -3.58 & 0.9070 \\
$\hat{A}(m)$ & -34.381 & -87.00 & -73.70 & -36.60 & -29.60 & 0.9360 \\
$\hat{F}(m)$ & 2.834 & & & 4.60 & 5.53 & 0.1550 \\
$\tilde{T}(m)$ & 913.873 & 223.45 & 369.51 & 1408.65 & 1930.47 & 0.6520 \\
\hline
\end{tabular}

Fractiles shown are the appropriate values for both one- and two-sided tests.

Table 4 - Test of the number $r$ of co-trending vectors

\begin{tabular}{rrrrr}
\hline$r$ & Test statistics & $10 \%$ critical region & $5 \%$ critical region & Conclusion \\
\hline 1 & 0.1635 & $>0.3518$ & $>0.4685$ & Accept \\
2 & 1.1329 & $>0.5356$ & $>0.6742$ & Reject \\
\hline
\end{tabular}




\section{References}

Barro, R.J. (1986). “The Behavior of the United States Deficit”, in Gordon, R.J. (ed.), The American Business Cycle, University of Chicago Press, Chicago.

Barro, R.J. (1987). "Government Spending, Interest Rates, Prices and Budget Deficits in the United Kingdom, 1730-1918”, Journal of Monetary Economics, 20, 221-247.

Bohn, H. (1998). "The Behavior of US Public Debt and Deficits", Quarterly Journal of Economics, 113, 949-963.

Breitung, J. (2002). "Nonparametric Tests for Unit Roots and Cointegration", Journal of Econometrics, 108, 343-364.

Bierens, H.J. (1993). "Higher Order Autocorrelations and the Unit Root Hypothesis", Journal of Econometrics, 57, 137-160.

Bierens, H.J. (1997). "Testing the Unit Root with Drift Hypothesis against Nonlinear Trend Stationarity, with an Application to the US Price Level and Interest Rate", Journal of Econometrics, 81, 29-64.

Bierens, H.J. (2000). "Nonparametric Nonlinear Co-trending Analysis, with an Application to Interest and Inflation in the U.S.", Journal of Business and Economic Statistics, 18, 323-337.

Bierens, H.J. (2002). "EasyReg International", Department of Economics, Pennsylvania State University, University Park, PA

Bierens, H.J. and Guo, S. (1993). "Testing Stationarity and Trend Stationarity Against the Unit Root Hypothesis", Econometric Reviews, 12,1-32.

Cushman, D.O. (2002). "Nonlinear Tends and Co-trending in Canadian Money Demand", Studies in Nonlinear Dynamics and Econometrics, 6, article 4. http://www.bepress.com/snde/vol6/iss 1/art4.

Engle, R.F. and Granger, C.W.J. (1987). "Co-integration, and Error Correction: Representation, Estimation, and Testing”, Econometrica, 55, 251-276.

Fratianni, M. and Spinelli, F. (2001). Storia monetaria d'Italia, Etas, Milano.

Giavazzi, F., Jappelli, T. and Pagano, M. (2000). "Searching for Non-linear Effects of Fiscal Policy: Evidence from Industrial and Developing Countries", European Economic Review, 44, 1259-1289.

Granger, W.J. and Hallman, J. (1991). "Long Memory Series with Attractors", Oxford Bulletin of Economics and Statistics, 53, 11-26.

Hamilton, J. and Flavin, M. (1986). "On the Limitation of Government Borrowing: A Framework for Empirical and Theoretical Testing", American Economic Review, 76, 808-819.

Hakkio, C. and Rush, M. (1991). “Is the Budget Deficit Too Big?” Economic Enquiry 29, 429-445.

Haug, A.A. (1995). "Has Federal Budget Deficit Policy Changed in Recent Years?" Economic Inquiry, 33, 104-118.

Istat (various years), Annuario Statistico Italiano, Roma.

Leachman, L.L. (1996). "New Evidence on the Ricardian Equivalence Theorem: A Multicointegration Approach", Applied Economics, 28, 695-704.

Kwiatkowski, D., P. Phillips, P. Schmidt, and Y. Shin (1992). "Testing the Null of Stationarity Against the Alternative of a Unit Root", Journal of Econometrics, 54, 159-178.

Manasse, P. (1996). “Are Taxes Too Low?”, Journal of Economic Dynamics and Control, 20, 1263-1288. 
Martin, G.M. (2000). "US Deficit Sustainability: A New Approach Based on Multiple Endogenous Breaks", Journal of Applied Econometrics, 15, 83-105.

McCullum, B.T. (1984). "Are Bond-Financed Deficits Inflationary? A Ricardian Analysis", Journal of Political Economy, 92, 123-135.

Newey, W.K. and West, K.D. (1987). "A Simple Positive Definite Heteroskedasticity and Autocorrelation Consistent Covariance Matrix", Econometrica, 55, 703-708.

Ouliaris, S., Park, J.K., and Phillips, P.C.B. (1989). "Testing for a Unit Root in the Presence of a Maintained Trend", in B. Raj, (ed.) Advances in Econometrics and Modelling, Dordrecht, Kluwer, 6-28.

Park, H.J. and Fuller, W.A. (1995). "Alternative Estimators and Unit Root Tests for the Autoregressive Process", Journal of Time Series Analysis, 16, 415-429.

Perron, P. (1989). "The Great Crash, the Oil Price Shock, and the Unit Root Hypothesis", Econometrica, 57, 1361-1402.

Phillips, P.C.B. and Perron, P. (1988). "Testing for a Unit Root in Time Series Regression", Biometrika, 75, 335-346.

Quintos, C.E. (1995). "Sustainability of the Deficit Process with Structural Shifts", Journal of Business and Economic Statistics, 13, 409-417.

Sarno, L. (2001). "The Behavior of US Public Debt: A Nonlinear Perspective", Economics Letters, 74, 119-125.

Sims, C. (1980). "Macroeconomics and Reality", Econometrica, 48, 1-48.

Trehan, B. and Walsh, C.E. (1990). "Seigniorage and Tax Smoothing in the United States, 1914-1986", Journal of Monetary Economics, 25, 97-112.

Wickens, M.R. and Uctum, M. (1993). "The Sustainability of Current Account Deficits. A Test of the US Intertemporal Budget Constraint", Journal of Economic Dynamics and Control, 17, 423-441.

Zivot, E. and Andrews, D.W.K. (1992). "Further Evidence on the Great Crash, the Oil Price Shock, and the Unit Root Hypothesis", Journal of Business and Economic Statistics, 10, 251-270. 